Anatolii S. Kondykov, Ph. D. in Philosophy, Professor, Honoured Worker of the Russian Federation Altai State Institute of Culture (Barnaul, Russia) sovetnik@agaki.ru

\title{
SOCIOLOGICAL ANALYSIS OF CURRENT STATE OF SOCIAL AND CULTURAL SECTOR IN ALTAI KRAI: MAJOR RESULTS
}

\begin{abstract}
Current task for achieving goal of the modern Russian state cultural policy is providing humanitarian and cultural development of the nation which is considered as a basis for quality renewing of a personality, for getting its preparedness and ability to dynamic participation in processes of public growth. One of the important direction here is qualitative development of social and cultural environment, improvement of its moral and psychological sphere, supporting of comfortable conditions for services consumers in social sphere. The paper outlines the key results of analysis of the main qualitative features of current status of social and cultural sphere of the Altai Krai in regional and municipal levels got within the frames of the author's research in 2019. For the first time, activities of services creation not only institutions of cultural sphere but also other actors of social sector chosen as an object of study; methodological base of the research includes axiological and civilizational approaches.
\end{abstract}

Keywords: humanitarian and cultural development, social and cultural sphere, social and cultural sphere quality monitoring, actors of cultural policy in social sphere, Altai Krai.

УДК 502.5/.8:314.122.66

DOI: $10.32340 / 2414-9101-2020-1-21-27$

В. И. Матис, доктор педагогических наук, профессор, почётный работник высшего профессионального образования Российской Федерации

Алтайский государственный институт культуры (Барнаул, Россия) vmatis@rambler.ru

\section{ОПЕРАЦИОНАЛИЗАЦИЯ ПОНЯТИЯ «ОКРУЖАЮЩАЯ СРЕДА» В СОХРАНЕНИИ И РАЗВИТИИ ЖИЗНЕННЫХ СИЛ ЭТНОСА}

Аннотация. На основе разрабатываемого в науке и практике образования поликультурного подхода рассматривается жизнедеятельность человека, этнической группы в антропологическом, акмеологическом и культурологическом аспектах. Поскольку для сохранения и развития жизненных сил этноса существенное значение имеет среда с её особенностями, значимыми в культуроформирующем отношении, возникает проблема адекватности окружающей среды для получения возможности сохранения и развития жизненных сил этноса. Эта адекватность предполагает соответствие потребностей и возможностей этноса требованиям процесса сохранения и развития жизненных сил этноса. Окружающая среда может оказывать как положительное, способствующее сохранению жизненных сил, их росту, так и отрицательное, деформирующее влияние на возможности развития этноса. Этот анализ проводится через наиболее значимую социально-культурную деятельность личности и этноса, которая определяет их образ мира.

Ключевые слова: жизненные силь, коммуникачионная среда, национальная среда, ограничения в сохранении и развитии жизненных сил этноса, окружающая среда, риски, сохра- 
нение и развитие жизненных сил этноса, соцчиальная среда, социиальн-культурная среда, среда обитания, этническая идентификация.

В связи с насыщенностью социально-культурными мероприятиями и разнообразием национально-культурных особенностей развития этносов в стране или отдельном регионе, объектом специального исследования может быть окружающая среда, от которой во многом зависит направление вектора развития этноса, его жизненные силы. Это довольно обширная сфера жизни этноса, а социальная реальность, подлежащая непосредственному изучению, выступает как предмет исследования: изучение особенностей сохранения и развития жизненных сил этноса; целью является выявление роли и особенностей окружающей среды в сохранении и развитии жизненных сил народа, проживающего в каждом конкретном регионе.

Операционализацию и категоризацию при таком подходе, следует, очевидно, начать с интегративного, сложного понятия «окружающая среда», включающего различные разновидности сред, в которых человек осуществляет свою деятельность. Операциональное определение окружающей среды следует выразить «как комплекс окружающих человека физических, географических, биологических, социальных, культурных и политических условий, который определяет форму и характер его существования» [1, с. 97]. В результате этого общество, этнос или отдельный человек, иными словами - все люди, а также все процессы, происходящие в этих структурах, тесно взаимосвязаны с окружающей средой, непосредственным образом влияющей на жизнь людей. Благодаря этому происходит затухание или процветание, застой или развитие социальной, демографической этнической группы или общества в целом.

Поскольку предметом нашего исследования является сохранение и развитие жизненных сил этноса, то в первую очередь следует рассмотреть социальную среду с позиций совокупности общественных отношений, складывающихся в обществе и оказывающих существенное влияние на этносоциальную структуру [2, с. 651]. В окружающую среду входят доминирующие общественные, этнокультурные, религиозные идеи и ценности. Причём благоприятной является та среда, в которой все составляющие ориентированы на творческое становление инициативной личности, как части этноса, что будет способствовать сохранению и развитию его жизненных сил.

Если предположить, что жизненные силы или жизненная энергия этноса - это волеизъявление, мобилизующее все ресурсы и преодолевающее все препятствия на пути развития, то сохранение жизненных сил этноса может определяться как процесс выявления роли и особенностей социально-культурных условий, создаваемых средой и последовательно проходящий определённые ступени приближения к цели.

Имеющиеся в распоряжении этноса ресурсы определяют возможности при выборе стратегии и тактических действий для сохранения и развития жизненных сил, но следует иметь в виду, что кроме собственно ресурсов на сохранение и развитие влияют и некоторые ограничения, характерные для данной системы. Такие ограничения могут порождаться нормативноправовым статусом этнического образования, действующим документооборотом, принятыми в стране законами, отраслевыми или государственными стандартами, а также моральными нормами, правилами поведения, традициями, обычаями, сложившимися на данной территории проживания и другими особенностями.

Следует также иметь в виду, что будущее, как правило, неизвестно, и все предпринимаемые этносом и государством действия связаны с определенными рисками, которые могут оказать влияние на социально-экономические процессы сохранения и развития этноса (рентабельность созданного этносом хозяйственного комплекса, доходы предприятий и членов 
общества, затраты на обеспечение производственного процесса, оборот и ликвидность производимой продукции, возможности всегда оплачивать счета и т. д.).

Окружающая среда и её влияние на мировоззренческое, профессиональное и нравственное становление личности и общества в целом «изучались и изучаются на теоретическом уровне и в форме конкретных исследований материальных, жилищных, бытовых и культурных условий жизни», что нашло отражение в трудах представителей многих наук $[3,4,5,6,15]$. Так исследователи убедительно доказывают, что на формирование сознания и мышления, их направленности на сохранение жизненных сил, уровня образованности, а также личностное развитие участников рассматриваемых процессов происходит не только под воздействием самой жизни, окружающей действительности, уже созданных и используемых, но и в результате целесообразно организованной педагогической деятельности.

Авторы ряда исследований представляют окружающую среду, с одной стороны, как совокупность объектов, вступающих во взаимодействие с какой-либо системой [7, с. 427], и совокупность оказывающих влияние на жизнедеятельность людей внешних условий (физических, социокультурных и др.), с другой стороны.

С этих позиций окружающая среда предстаёт сложной системой, которая включает в жизнь самого человека, поскольку человека формирует именно среда, где он живёт, растёт и развивается.

В состав окружающей среды, как многокомпонентной системы, входит и социальная среда - окружающий человека социальный мир, «включающий в себя общественные (материальные и духовные) условия становления существования, развития и деятельности людей, неразрывно связанные с общественными отношениями, в которые эти люди вовлечены» $[8$, с. 97].

Социальную среду социологи, например, «понимают совокупность индивидов, кругов, групп и других общностей, с которыми личность сталкивается на протяжении своей жизни». Тем не менее, ряд исследователей «в социальной среде упускают из виду социальную сущность вещей, совокупность которых составляет предметную (или материально-вещную) сторону социальной среды» $[9$, с. 55].

Предметом научного анализа различных исследователей процессов становления личности - философов, педагогов, социологов, психологов - становились различные аспекты профессионального становления человека, мотивов его выбора в этой сфере. К таким аспектам можно отнести влияние на формирование личности окружающей среды, экономические проблемы образования, неудовлетворённость трудом, заработной платой и др. С этой целью проводились панельные исследования и регулярный мониторинг с целью выяснения динамики социальных условий жизни, социально-психологического самочувствия, формирования ценностных установок и т. д. [3, 6, 10, 11].

Так или иначе, обозначенные процессы касаются социальной среды, во многом определяющей своеобразие личности, формирование её особенностей и индивидуальность. Важность исследуемой проблемы определяется пониманием того, что социальная среда осуществляет значительное воздействие на личность и является своеобразной основой формирования человека, источником восприятия личностью общественных норм, культурных ценностей, социальных ролей и т. д.

Эти особенности тесно связаны с тем или иным историческим этапом, они могут меняться в соответствии с изменением социокультурной, общественно-политической ситуации в обществе, изменением физических и экономических условий проживания, формированием новых жизненных установок и стереотипов и т. д. В связи с этим важным фактором сохранения и развития жизненных сил является социально-культурная среда, которая понимается как совокупность различных (макро-, мезо- и микро-) условий сохранения и развития культуры, социальной сферы, экономики, в которых живет и развивается этнос, формируются его 
жизненные силы. Эта среда является существенным условием функционирования, сохранения и развития общества в целом.

В педагогике социальная среда употребляется в нескольких смыслах, соответствующих полноте воздействия на личность:

- во-первых, это всеобъемлющая социальная действительность - общество, государство в целом (макроуровень);

- во-вторых, это региональная среда, включающая этнокультурную специфику, уровень развития экономики и инфраструктуры конкретной местности (мезоуровень);

- в-третьих, среда непосредственного окружения человека (образовательная организация, трудовой коллектив, семья, личное окружение), также в той или иной степени оказывающая влияние на становление и развитие его социальных, профессиональных и личностных качеств (микроуровень) [12, 13].

Социальную среду подразделяют на отдельные виды. Так, например, «социальнокультурная среда» в настоящее время становится одним из ключевых понятий в жизни всего народа, когда происходит его становление, определение жизненных планов и рассматривается как один из основных факторов развития общества.

Иной разновидностью окружающей среды является среда обитания, предстающая как «совокупность природных и социальных условий, в которых протекает жизнедеятельность человеческого общества» [7, с. 619] и включающая социально-культурные традиции, главенствующие научные представления о мире. Эти компоненты непосредственно оказывают влияние на формирование сознания, возникают в результате восприятия произведений литературы, искусства, массовой культуры. Для того чтобы сохранить существующее национальнокультурное разнообразие в обществе в целом или отдельных его регионах реализуются специально созданные проекты. К подобным акциям можно отнести, например, информационный проект «Национальная среда», который предназначен для популяризации и развития национальных культур, языков, формирования международных связей и взаимодействия в различных областях. Обнародование итоговых материалов проекта «Национальная среда», проведение различных форумов, брифингов, публикации в СМИ, например, в «Парламентской газете» вызывают значительный интерес у читателей, ставящих перед собой задачи сохранения и развития жизненных сил этноса.

Национальная среда является благоприятной почвой для формирования сущностных качеств личности, «это совокупные условия проявления в жизненной практике человека объективных и субъективных факторов, принявших своеобразную, конкретноисторическую форму общественного бытия» народа - его традиции, обычаи, поведенческие нормы и т. д., способствующие социализации и включению в социально-культурную ситуацию [14, с. 250].

Большое влияние на процесс становления личностных качеств оказывает этническая идентификация, которая, как отмечает Е. В. Благовская, выступает как «процесс интеграции личности в этнос, предполагающий принятие этнического происхождения и осознание принадлежности к конкретному этносу, приобщение к её этническим признакам и осознание человеком статуса и роли данной этнической общности, что осуществляется через институты трансляции социального опыта данного этноса, являющимися институтами этнической идентификации» $[15$, с. 7$]$. В этом смысле этническая идентификация не только сохраняет, но и развивает жизненные силы этноса.

Не менее важной в сохранении и развитии жизненных сил этноса является среда коммуникационная, представляющая собой определённый процесс формирования и самоопределения личности в поликультурном пространстве. Развитие личности в этом случае - освоение внешней социальной деятельности на диалогической основе, так как «сформулировать свою точку зрения невозможно, не воспроизведя в ней иные способы понимания» $[6$, c. 10]. 
Производя операционализацию данного понятия, сформулируем рабочее определение коммуникационной среды, представив его как «совокупность условий, позволяющих группе людей/ организаций (субъекты среды) реализовывать желание и необходимость обмена информацией путём прямого обращения друг к другу для сохранения и развития этнических особенностей и жизненных сил» [16, с. 66].

Достаточно распространены научные работы, в которых принижается роль региональной социально-культурной среды, содержащей в себе общественные (материальные и духовные) условия возникновения, существования, развития личности. По мнению Ж. Т. Тощенко, «материально-вещественные элементы, которые должны обеспечить общие условия деятельности человека в быту и семье» $[17$, с. 27$]$ имеют существенное значение в исследуемом показателе. В эти условия входят жилище с соответствующей инфраструктурой, сфера торговли и общественного питания, транспортное сообщение и т. д.

В отдельные периоды истории нашего государства, когда допускались гонения на церковь или пренебрежительное отношение к изучению истории, культуре и народным языкам, в особенности их диалектным формам, у некоторых этносов не благодаря официальной национальной и культурной политике, а вопреки ей (в семьях, общинах) сохранялись этнические особенности, обычаи, традиции и культура народов. В современных условиях, когда политика государства направлена на сохранение и развитие жизненных сил этносов, наличие объектов социально-культурной деятельности (клубы, кружки, курсы, театры, спортивные сооружения и т. д.), вовлечение в их работу людей разных культур, имеют существенное значение и влияние на формирование ценностных ориентаций, предоставление возможностей к развитию способностей и желаний у подрастающего поколения к сохранению и развитию жизненных сил.

Таким образом, социально-культурная среда проживания людей, включающая в себя современные типичные формы взаимоотношений и поиск путей формирования взаимного уважения, доверия, заинтересованности, действенной взаимопомощи молодого и старшего поколений являются важным звеном сохранения и развития жизненных сил этноса. Это подтверждается результатами массовых опросов, глубинных интервью и экспертных оценок, осуществляемых в рамках научной школы «Поликультурный подход в образовании и культурной сфере». Итоги выявили обусловленности экономического и социального статуса, демографического положения, образовательного уровня специфическими условиями окружающей среды и влиянием этих показателей на профессиональный уровень, на личностное развитие респондента, его сознание и мышление, на его образ мира, а через эти показатели и на жизненные силы этноса.

Таким образом, операционализируя понятие «окружающая среда», в широком толковании термина можно согласиться с мнением Т. 3. Адамьянц - «это совокупность культурных ценностей, общепринятых норм, законов, правил, научных данных и технологий («ноу-хау»), которыми располагает социум и человек для эффективных действий и взаимодействий со всеми компонентами своей жизненной среды» [3, с. 1]. Именно в этом смысле и в наших исследованиях используется это рабочее определение.

\section{Сиисок литературы}

1. Бабушкин, С. С. Управление качеством окружающей среды: история развития современного подхода // Устойчивое инновационное развитие: проектирование и управление. - 2017. - Т. 13. - № 1. - С. $96-$ 121.

2. Социальная среда // Философский энциклопедический словарь / гл. ред. Л. Ф. Ильичёв [и др.]. Москва : Сов. энциклопедия, 1983. - С. 651.

3. Адамьянц, Т. 3. Поколение «возраста зрелости» в современной социокультурной среде: социальная диагностика // Спутник ежегодника «Россия реформирующаяся» / Федер. науч.-исслед. социологический центр Рос. академии наук. - Москва, 2014. - URL: https://www.isras.ru/files/el/sputnik_2014/htm/menu.htm (15.02.2020 г.). 
4. Григорьев, С. И. Культурвитализм и виталистская социология - концептуальная основа анализа современной национально-культурной, производственно-экономической и социально-территориальной дифференциации населения регионов России / С. И. Григорьев, О. В. Даровских, А. С. Гришина // Уровень жизни населения регионов России. - 2016. - № 1. - С. 39-46.

5. Григорьев, С. И. Особенности экспертной оценки развития основных форм общественного сознания населения современной России: контекст изменений информационного социокультурного пространства развития жизненного потенциала личности // Информация и образование: границы коммуникаций. - 2013. № 5. - С. 193-194.

6. Кутявина, Е. Е. Разноэтническая семья как среда формирования этнической идентичности личности // Вестник Нижегородского университета им. Н. И. Лобачевского. Сер. Социальные науки. - 2010. № 2. - С. 47-52.

7. Яценко, Н. Е. Обществоведческий словарь. - Изд-е 4, испр. и доп. - Санкт-Петербург : Печ. Двор, 2009. $-784 \mathrm{c}$.

8. Немировский, В. Г. Социология личности: теория и опыт исследования. - Красноярск : Изд-во Краснояр. ун-та, 1989. - 193 с.

9. Матис, В. И. Влияние среды на формирование поликультурного сознания и мышления личности // Вестник Алтайского государственного педагогического университета. - 2018. - № 3. - С. 54-58.

10. Золотова, Т. Н. Праздничная культура как фактор формирования идентичности // Проблемы историко-культурной идентичности в полиэтнических обществах : тез. докл. всерос. науч. школы (Омск, 6-8 сент. 2011 г.). - Омск : Изд-во Ом. гос. ун-та, 2011. - 19 с.

11. Коган, М. Э. Роль межэтнических коммуникаций и национальных ориентаций при передаче этнической культуры // Изучение преемственности этнокультурных явлений : [сб. ст.]. - Москва : ИЭ, 1980. C. 5-15.

12. Матис, В. И. Культура межнационального общения в системе социально-национальных связей на Алтае : учеб. пособие. - Барнаул : Изд-во Алт. гос. ин-та культуры, 2017. - 316 с.

13. Матис, В. И. Педагогика межнационального общения : учебник. - Барнаул : Изд-во БГПУ, 2003. $510 \mathrm{c}$.

14. Матис, В. И. Методологические проблемы науки и научного проектирования // Мир науки, культуры, образования. - 2013. - № 5. - С. 248-251.

15. Благовская, Е. В. Этническая идентичность как основа формирования институтов этнической идентификации в республике Алтай: социально-философский анализ : автореф. дисс. ... канд. филос. наук: 09.00.11. - Чита, 2013. - 22 с.

16. Левченко, Д. В. Сетевое взаимодействие в информационной среде как средство самореализации будущего педагога // Известия Волгоградского государственного педагогического университета. - 2014. № 4. - С. 65-70.

17. Тощенко, Ж. Т. Социальная инфраструктура: сущность и пути развития.-Москва : Мысль, 1980. $-206 \mathrm{c}$.

Vladimir I. Matis, Dr. of Pedagogical Sciences, Professor, Honoured Worker of Higher Professional Education of the Russian Federation Altai State Institute of Culture (Barnaul, Russia) vmatis@rambler.ru

\section{OPERATIONALIZATION OF CONCEPT "ENVIRONMENT" IN PRESERVATION AND DEVELOPMENT OF AN ETHNOS' VITALITY}

\footnotetext{
Abstract. The paper considers a human's and an ethnic group's activity in anthropological, acmeological, and cultural aspects through the prism of multicultural approach. Environment with all of its peculiarities plays a significant role in an ethnos' life, so the is a problem of adequacy of an environment to an ethnos' opportunities and needs in preserving and developing vital forces of an ethnic community. Environment influences on an ethnos' vital forces positively (supporting vitality) or negative (misshaping it). This analysis takes into account the most meaningful sorts of social and cultural activities of a personality and an ethnos that defines their picture of the world.
} 
Keywords: vital forces, communicative environment, ethnic environment, barriers for preservation and development of an ethnos' vitality, social environment, social and cultural environment, environment, ethnic identification.

УДК 130.2:[398.5:316.347]

DOI: $10.32340 / 2414-9101-2020-1-27-33$

О. В. Первушина, кандидат культурологии, доцент Алтайский государственный институт культуры (Барнаул, Россия) agaki-pervushina@yandex.ru

\section{ЭТНИЧЕСКАЯ КАРТИНА МИРА: ФИЛОСОФСКО-КУЛЬТУРОЛОГИЧЕСКИЕ АСПЕКТЫ ИССЛЕДОВАНИЯ}

Аннотация. В статье с позиций философско-культурологического подхода предпринята попытка уточнения содержания научного концепта «этническая картина мира», выявление её основных смысловых констант на примере анализа представлений о мире кочевых тюркско-монгольских этносов Южной Сибири и Монголии. Определены ключевые знаковосимволические образы, взаимосвязь которых образует этническую картину мира, рассматриваемая автором статьи в качестве семиосферы.

Ключевые слова: этническая картина мира, этнос, знаки, символь, семиосфера, феноменологический метод, пространство, время, миф.

Этническая картина мира воплощает и сохраняет историко-культурный опыт бытия этноса во времени и пространстве, представляя собой результаты адаптации человеческого сообщества к определённой экосистеме, запечатлённые в языке, обычаях, традициях, религиозных практиках, образе жизни. Этнические культуры - древнейший тип культуры, их формирование и развитие связано с историческим становлением этносов и формированием культурных форм, которые носят стабилизирующий, объединяющий характер, способствующий устойчивости этноса перед лицом природных, социальных, исторических вызовов. Процесс эволюции каждого этноса во времени и пространстве порождал только ему присущие модели «образа мира», чем объясняется богатство и разнообразие этнических культур в мире.

В пространстве современной глобальной инновационной культуры, в основе которой лежат ценности научного познания, абстрактно-логического мышления, прагматизма и рациональности не потерял значение опыт этнического сознания как сознания, основанного на иных способах восприятия и оценки окружающего мира - интуиции, откровения, вчуствования, образного эмоционального переживания, фантазии.

Представители современного социально-гуманитарного знания - этнологи, антропологи, лингвисты, культурологи обращаются к опыту этнических культур как уникальному знаковосимволическому образованию, которое имеет ценность и значимость не только для этноса его породившего, но и носит универсальный, общекультурный характер, так как это позволит не только осознать свою связь с культурным опытом прошлого, определить соотношение мемориального и актуального в его структуре, но и, что особенно важно, включить этот опыт в современную картину мира человека глобальной культуры, что способно, на наш взгляд, повлиять на устойчивость современного культурного мира как личностного, так и надличностного.

Исследование концепта «картина мира» в культурологии основано на привлечении междисциплинарного дискурса. Процессы антропогенеза, этногенеза и культурогенеза лежат в основе формирования многообразных этнических культур в мире и, соответственно, спосо- 